$\$$ Research Square

\title{
Wind speed persistence at the Fernando de Noronha archipelago, Brazil
}

\author{
Allan Robert Silva ( $\square$ allan.robert.statistical@gmail.com ) \\ Universidade Federal de Sergipe https://orcid.org/0000-0001-5733-7438 \\ Tatijana Stosic \\ Universidade Federal Rural de Pernambuco \\ Borko Stosic \\ Universidade Federal Rural de Pernambuco
}

\section{Research Article}

Keywords: wind speed, Era5, persistence, duration curve, conditional probability, persistence probability

Posted Date: February 17th, 2021

DOl: https://doi.org/10.21203/rs.3.rs-194860/v1

License: (1) This work is licensed under a Creative Commons Attribution 4.0 International License. Read Full License

Version of Record: A version of this preprint was published at Theoretical and Applied Climatology on February 24th, 2021. See the published version at https://doi.org/10.1007/s00704-021-03571-7. 


\title{
Wind speed persistence at the
}

\section{Fernando de Noronha archipelago, Brazil}

\author{
Allan Robert Silva ${ }^{\mathrm{a}}$, Tatijana Stosic ${ }^{\mathrm{b}}$ and Borko Stosic ${ }^{\mathrm{b}}$ \\ ${ }^{a}$ Departamento de Estatística e Ciências Atuariais, Universidade Federal de Sergipe, Campus \\ Universitário José Aloísio de Campos, 49100-000, São Cristovão-SE, Brasil \\ ${ }^{b}$ Departamento de Estatística e Informática, Universidade Federal Rural de Pernambuco, \\ 52171-900, Recife-PE, Brasil
}

Corresponding Author: Dr. Allan Robert Silva

\begin{abstract}
The use of wind energy has been growing worldwide continuously over the last years due to global efforts to combat climate change. The modern turbines are becoming ever more cost effective, and are gaining features that aim to reduce further the impact on the environment, such as reducing noise or increasing the height. In this context, the current study investigates the persistence of wind in Fernando de Noronha archipelago, an important Brazilian ecological site, using hourly wind speed data at $100 \mathrm{~m}$ height. To this end, data from Era5 reanalysis were used, as they present high resolution and good performance in estimating meteorological data, and two well-known methods were applied to quantify wind persistence: duration curve and conditional probability. In addition, a novel method is proposed regarding persistence probability of periods of viable energy generation. The results obtained show that Fernando de Noronha archipelago presents rather high wind persistence on a monthly scale, with considerably long intervals of wind speed useful for wind power generation.
\end{abstract}

Keywords: wind speed, Era5, persistence, duration curve, conditional probability, persistence probability

\section{1- Introduction}

The use of wind energy has been growing worldwide at an exponential rate over the last decades, primarily due to the lack of emission of greenhouse gases. Moreover, wind energy generation is viable in remote locations, and the cost of investing in wind turbines has decreased to the point of making this energy source competitive with other (often subsidized) sources. Novel models of wind turbines are being developed in order to obtain greater power, and at the same time further reduce the impact on the environment. Most new models tend 
to be more powerful and quieter (Møller H and Pedersen 2011; Jamieson 2018), while other models were created with greater height (Caduff et al. 2012), and even models without propellers have been designed (Chizfahm et al. 2018).

Globally, an average yearly increase of $71 \mathrm{GW}$ of wind energy installations is expected by 2024 (Global Wind Energy Council 2019). In 2019 there were 60.4GW new wind energy installations, bringing the world production capacity to $651 \mathrm{GW}$. Brazil was the fifth country that has invested the most in wind energy, adding $744.95 \mathrm{MW}$ in 2019 to its electric power grid to bring the installed capacity to $15.45 \mathrm{GW}$, which represents $9.1 \%$ of the nation's power matrix (Brazilian Wind Energy Association 2019).

The implementation of wind farms requires a number of preliminary studies to estimate the characteristics of the wind speed and wind energy potential. To find the ideal location for wind energy production both the magnitude and the persistence of wind speed have to be taken into account (Koçak 2008; Cancino-Solórzano et al. 2010). Most studies are focused on selection of the best wind speed distribution function (Morgan et al. 2011; Soulouknga et al. 2018; Ouarda and Charron 2018; Ouarda et al. 2015; Mazzeo 2019), while persistence properties of wind dynamics have been far less explored (Koçak 2008; koçak 2009; CancinoSolórzano et al. 2010; Santos et. al. 2012).

Fernando de Noronha archipelago is an important ecological site, located in the Atlantic Ocean, $360 \mathrm{~km}$ offshore from the Brazilian coast. Administratively it belongs to the state of Pernambuco, and is divided in two conservation units: National Marine Reserve (retained for fauna, flora and natural resources protection) and the Environmental Protected Area which is reserved for human occupation. Each of these units has distinct preservation rules established by the federal and the state governments, with the goal of preservation of natural resources. It was the site of the first large wind turbine for commercial operation installed in South America in 1992 (Araújo and Freitas 2008), but it was (unfortunately) destroyed by lightning in 2009. Currently the energy supply for the island comes mainly from diesel generators, and there has been a long-standing effort to develop efficient technological solutions for energy supply based on integration of wind and solar resources (Rosas 2013).

In this work we analyze persistence properties of wind speed at the location of Fernando de Noronha Island in order to contribute to the development of a reliable scientific base for evaluation of renewable energy potential at this location. We use statistical methods wind speed duration curve (WSDC) and conditional probability approach (CPA) (Koçak 2008), and we propose a novel approach, that we term "Persistence probability curve", that yields the identical persistence threshold level as CPA, but also offers an additional insight into the persistence properties of the wind speed series (stretches of time viable for energy production), at different scales. 


\section{2- Materials and methods}

The location of the Fernando de Noronha archipelago is shown in Fig. 1.

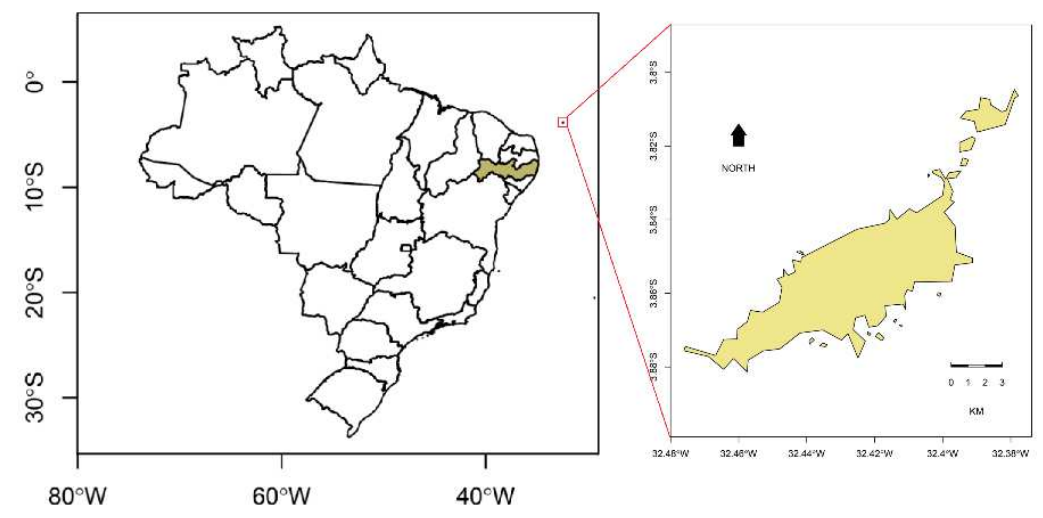

Figure 1. Map of Brazil highlighting the state of Pernambuco, and zoom of the Fernando de Noronha island.

The division Center for Time Prevision and Climatic Studies (Centro de Previsão de Tempo e Estudos Climáticos-CPTEC) of the Brazilian National Institute for Space Research (Instituto Nacional de Pesquisas Espaciais-INPE) provides historical meteorological data for Brazil. There is a meteorological station installed at Fernando de Noronha island, that collects wind speed data with 3 hour frequency, but after careful examination of the available database we found that it is not suitable for our purposes due to low quality (there are a lot of missing data, and various long periods of several months show the same values of wind speed).

Other data sources that have been extensively used in both academia and industry for modelling wind power are outputs from meteorological reanalysis (Holt and Wang 2012; Olauson and Bergkvist 2015; Archer and Caldeira 2009; Cannon and Brayshaw 2015). Reanalysis are consistent gridded datasets for a long record of time (typically more than 30 years) which are result of combining a state-of-the-art numerical model with the observations from several sources. These datasets allow inferring features such as variability or trends for regions or variables where in situ observations are lacking (Chadee and Clarke 2014). In this work we chose ERA5 reanalysis because of high spatial $(\sim 30 \mathrm{~km})$ and temporal (1 hour) resolution, and availability of wind speed series at hub height of $100 \mathrm{~m}$. This reanalysis was shown to perform well in representing the wind speed features at turbine hub heights (Ramon et al. 2019) and modelling wind power, both for countries and for individual wind turbines (Olauson J 2018). While both of these works demonstrate advantage of ERA5 over MERRA2 (which has been a de-facto standard in numerous studies), they do not include Brazil in the study area. A recent validation of the reanalysis data was performed (Gruber et al. 2020) for different regions including Brazil, and it was also found that the newer ERA5 reanalysis outperforms MERRA-2. The data were downloaded for latitude -3.85 and longitude -32.42 (Copernicus Climate Change Service - C3S). 
The hourly data from the ERA5 reanalysis of the orthogonal components of wind $u$ (eastward) and $v$ (northward) at $100 \mathrm{~m}$ height for 20 years (between 1 January 2000 to 31 December 2019) were collected for the island of Fernando de Noronha. The value of interest here is the wind speed, obtained as $\sqrt{u^{2}+v^{2}}$, and the resulting wind speed series are presented in Figure 2.

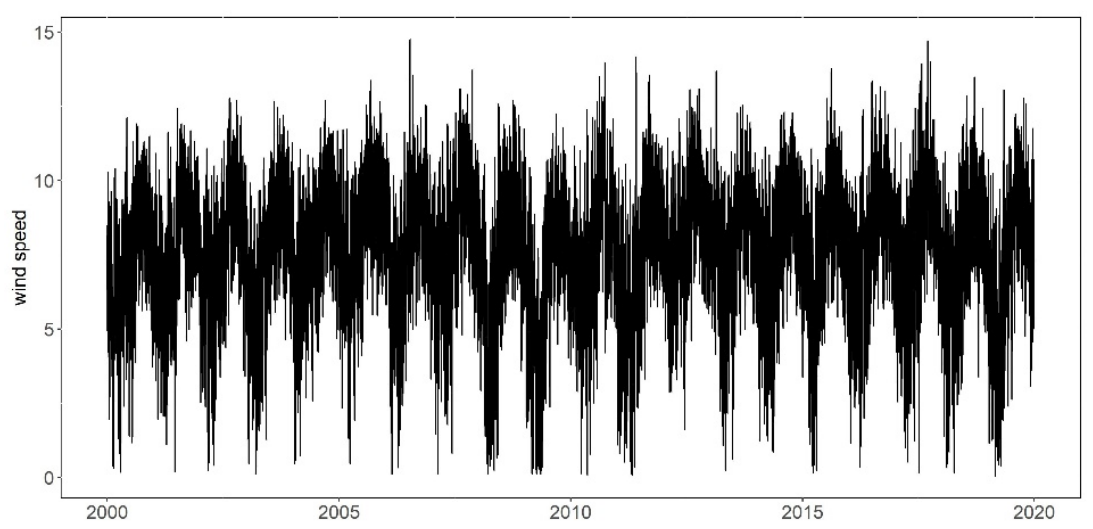

Figure 2. Time wind speed reanalysis series ERA5 at $100 \mathrm{~m}$

Three methods were applied to estimate the wind persistence two of which have been widely used (Koçak 2008; Cancino-Solórzano et al. 2010; Masseran et al. 2012; Kulkarni et al. 2015; Korkmaz and Koçak 2017), and the last being a novel proposal of this study. The methods used were implemented with $\mathrm{C}$ programming and the figures were elaborated in software $\mathrm{R}$. In what follows these methods are described in some detail.

\subsection{Wind speed duration curves - WSDC}

The wind speed duration curve (Koçak 2008) is the two-dimensional graphical presentation of wind speed (vertical axis) and the percentage of time that wind speed is equal to or greater than a certain value (horizontal axis). Given the sequence of $n$ wind speed data which are arranged in ascending order, and denoting by $v_{i}$ wind speed of the $i-t h$ ordered observation, the percentage of time wind speed is equal to or greater than each particular value $v_{i}$ is

$$
\hat{P}\left(v_{i}\right)=\frac{n-i+1}{n} \cdot 100 \quad i=1,2, \ldots, n .
$$

On the WSDC plot, the value $P\left(v_{i}\right)$ which corresponds to a particular truncation level $v_{i}$ (ex. cut-in wind speed at which turbine starts generating electricity from turning), can be used as an indication of the persistence of wind: greater $P\left(v_{i}\right)$ values correspond to higher persistence of wind above truncation level. 


\subsection{Conditional probability approach - CPA}

The conditional probability approach (CPA) was proposed by Kocak (2008) for quantifying wind speed persistence, and has been subsequently used in a number of works (Cancino-Solórzano et al. 2010; Kulkarn et al. 2015). Given a time series of wind speed observations (ex. at hourly frequency), choosing a threshold level of interest (e.g. cut-in speed - the minimum wind speed necessary for energy generation, that generally varies between 3 and 4 meters per second), one can assign to the instances, with wind speed values equal or greater than the threshold level, an attribute "windy" $(W)$, and for wind speed values below the threshold an attribute "calm" $(C)$. The conditional probability that a "windy" hour follows another "windy" hour can be estimated as

$$
\hat{P}\left(x_{(t)}=W \mid x_{(t-1)}=W\right)=\frac{\text { number of } W^{\prime} \text { s following } W^{\prime} s}{\text { total number of } W^{\prime} s}=\frac{n_{W W}}{n_{W}},
$$

where $n_{W W}$ represents the number of pairs of consecutive time steps in which wind speed belongs to category $W$, and $n_{W}$ represents the total number of time steps with wind speed in category $W$. Although conditional probability value in (2) provides information about wind persistence, it is limited to only a single time step ahead. This can be improved by including more previous wind speed values in the calculation of conditional probability. More precisely, by denoting $n_{W}(q)$ the number of subsequences of $W^{\prime} s$ (words) of length $q$ (so that $n_{W}(1) \equiv n_{W}, n_{W}(2) \equiv n_{W W}$, etc.), conditional probability of a word of length $q$ is given by

$$
\hat{P}\left(x_{(t)}=W \mid x_{(t-1)}=W, x_{(t-2)}=W, \ldots, x_{(t-q)}=W\right)=\frac{n_{W}(q+1)}{n_{W}(q)},
$$

and the cutoff value $q_{0}$ for which this probability becomes equal to zero

$$
\hat{P}\left(x_{(t)}=W \mid x_{(t-1)}=W, x_{(t-2)}=W, \ldots, x_{\left(t-q_{0}\right)}=W\right)=0
$$

is directly related to persistence: the greater $q_{0}$ values correspond to higher persistence. Graphically, q values are shown on the $x$ axes and the corresponding conditional probabilities on the $y$ axes.

\subsection{Persistence probability - PP}

While the CPA approach yields the cutoff length $q_{0}$ of the largest subsequence of consecutive values above a given threshold (which quantifies persistence), for wind speed series with long stretches of values above the threshold, it yields values close to unity for most of the $q$ values, which does not reflect well the intermediate $q$ behavior of the sequence.

We find that a more informative measure, that yields the identical $q_{0}$ cutoff, is the probability of finding a sequence of length $q$ of consecutive values above the threshold, given by 


$$
\hat{P}_{P}\left(x_{(t)}=W, x_{(t-1)}=W, x_{(t-2)}=W, \ldots, x_{(t-q+1)}=W\right)=\frac{n_{W}(q)}{n-q+1}
$$

where the value $n-q+1$ in the denominator corresponds to the total number of words of length $q$ in the sequence of length $n$. By construction this quantity, which we denote here "persistence probability", yields the same cutoff value $q_{0}$ as CPA

$$
\hat{P}_{P}\left(x_{(t)}=W, x_{(t-1)}=W, x_{(t-2)}=W, \ldots, x_{\left(t-q_{0}\right)}=W\right)=0,
$$

but the graph of $\hat{P}_{P}(q)$ versus $q$ also yields additional information on stretches of different lengths of values above threshold, encountered in the series.

To demonstrate the advantage of PP over CPA, consider a simple example of hourly wind speed data for a year, with $24 \times 365=8760$ observations, in which there is a single week ( $7 \times 24=168$ observations) below the threshold (not useful for wind power generation). Consider now ordering these data in two ways so that the first group (G1) starts with 3949 W's, followed by 168 C's, and ends with 4634 W's, while the second group (G2) starts with $2000 \mathrm{~W}$ 's followed by $100 \mathrm{C}$ 's, then 1949 W's followed by $68 \mathrm{C}$ 's, and ends with $4634 \mathrm{~W}$ 's. Note that both groups were ordered so that the cutoff value is $q_{0}=4634$ for both CPA and PP. On the left panel of Figure 3 it is seen that the CPA graphs do not distinguish between the two groups, while the PP graphs on the right panel demonstrate rather different behavior, showing that e.g. the probability of having three months $(90 \times 24=2160)$ of continuous data above the threshold is much higher for the first group than for the second group.
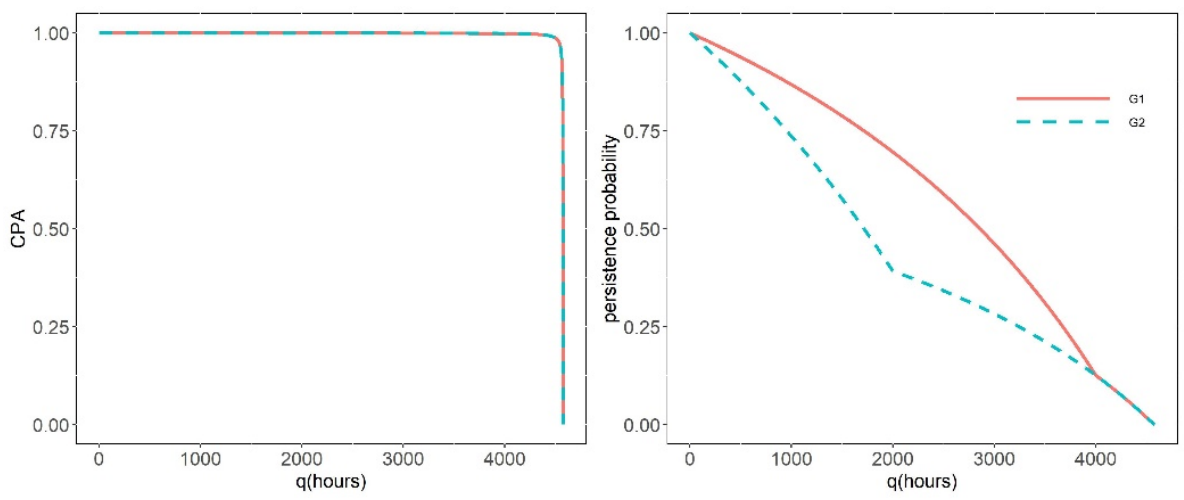

Figure 3. CPA (left panel) and PP (right panel) for G1 and G2 groups (see text).

It should be noted that both CPA and PP are trivially generalized for situations where both the lower bound (cut-in wind speed) and the upper bound (cut-out) are necessary, simply by implementing the adequate criterion for useful speed (attributing label "U" for "useful", rather than "W" for "windy"). 


\section{Results and discussions}

In Table 1 the descriptive statistics is presented for the Fernando de Noronha wind speed data at $100 \mathrm{~m}$ on monthly level. The overall average wind speed is $7.56 \mathrm{~m} / \mathrm{s}$ with a standard deviation of $2.09 \mathrm{~m} / \mathrm{s}$. Henceforth, cut-in of $4 \mathrm{~m} / \mathrm{s}$ will be used. The months from August to December show high average with minimums close to, or even above the cut-in (as September and November). In Figure 4 the wind speed distributions per month are shown, highlighting that the months from August to December have lower variability and a higher average than the others.

Table 1. Descriptive statistics of the Fernando de Noronha wind speed data.

\begin{tabular}{l|ccccccc}
\hline Month & Minimum & $1^{\circ}$ Quartile & Median & Mean & $3^{\circ}$ Quartile & Maximum & $\begin{array}{c}\text { Standard } \\
\text { Deviation }\end{array}$ \\
\hline January & 0.45 & 5.71 & 7.03 & 6.81 & 8.01 & 11.77 & 1.73 \\
February & 0.11 & 5.11 & 6.36 & 6.31 & 7.65 & 13.68 & 1.90 \\
March & 0.05 & 4.42 & 5.93 & 5.78 & 7.19 & 11.73 & 2.02 \\
April & 0.09 & 4.29 & 5.70 & 5.64 & 7.05 & 12.38 & 2.03 \\
May & 0.08 & 5.36 & 6.71 & 6.52 & 7.84 & 14.14 & 1.95 \\
June & 0.18 & 6.16 & 7.28 & 7.25 & 8.43 & 13.54 & 1.73 \\
July & 0.16 & 7.08 & 8.21 & 8.16 & 9.25 & 14.75 & 1.68 \\
August & 3.30 & 8.19 & 9.17 & 9.11 & 10.10 & 13.77 & 1.43 \\
September & 4.48 & 8.41 & 9.30 & 9.30 & 10.19 & 14.68 & 1.33 \\
October & 3.38 & 8.16 & 9.10 & 9.04 & 9.97 & 14.01 & 1.31 \\
November & 4.66 & 7.94 & 8.71 & 8.72 & 9.51 & 13.73 & 1.16 \\
December & 3.06 & 7.11 & 8.05 & 7.96 & 8.87 & 12.08 & 1.31 \\
\hline General & 0.05 & 6.29 & 7.78 & 7.56 & 9.04 & 14.75 & 2.09 \\
\hline
\end{tabular}

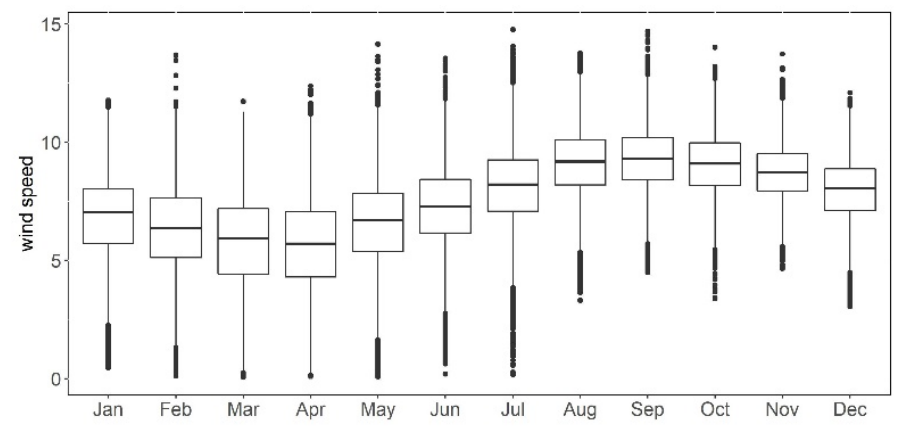

Figure 4. Wind distribution at 100m from Fernando de Noronha per month from 01/01/2000 to $12 / 31 / 2019$. 
To identify the probability distribution that best describes the wind speed data, we consider here the three distributions that are mostly used to model wind speed: Weibull, Gamma, and Generalized Gamma (Ouarda et al. 2015; Laib M et al. 2018), as listed in Table 2.

Table 2. Distributions most commonly used for modelling wind speed data.

\begin{tabular}{|l|l|l|}
\hline Distributions & Density function & Parameters \\
\hline Weibull & $f(x, k, c)=\frac{\beta}{\theta}\left(\frac{x}{\theta}\right)^{\beta-1} e^{-(x / \theta)^{\beta}}, x>0$ & $\begin{array}{l}\beta, \theta>0, \beta \text { is the shape and } \\
\theta \text { is the scale }\end{array}$ \\
\hline Gamma & $f(x, k, \beta)=\frac{\theta^{-k} x^{k-1} e^{-(x / \theta)}}{\Gamma(k)}, x>0$ & $\begin{array}{l}k, \theta>0, k \text { is the shape, } \theta \text { is } \\
\text { the scale and } \Gamma(.) \text { is the } \\
\text { gamma function }\end{array}$ \\
\hline $\begin{array}{l}\text { Generalized } \\
\text { Gamma }\end{array}$ & $f(x, k, \theta, \beta)=\frac{\beta \theta^{-\beta k} x^{\beta k-1} e^{-(x / \theta)^{\beta}}}{\Gamma(k)}, x>0$ & $\begin{array}{l}k, \beta, \theta>0, k \text { and } \beta \text { are } \\
\text { shape, } \theta \text { is the scale and } \\
\Gamma(.) \text { is the gamma function }\end{array}$ \\
\hline
\end{tabular}

In Figure 5 we show the histogram of the wind speed data from Fernando de Noronha, and the curves of the adjusted distributions. Using the Akaike information criterion (AIC) and Bayesian information criterion (BIC) it is found that the generalized Gamma distribution is the best for fitting the data, with parameters $k=0.48, \theta=9.71$, and $\beta=6.79$.

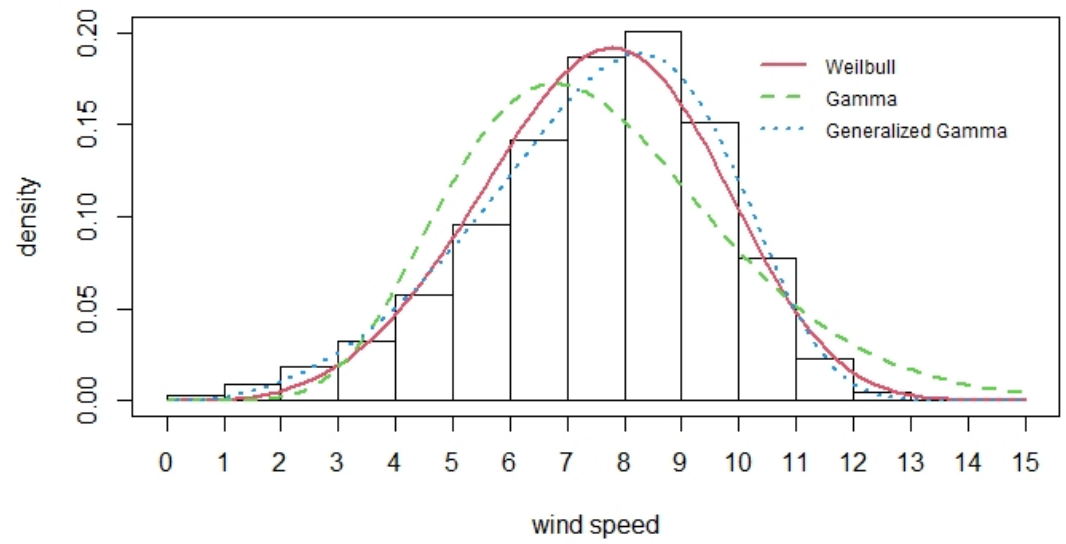

Figure 5. Histogram of the wind speed data with distributions fits.

Figure 6 shows the WSDC curve for wind speed data. Approximately 94\% of the speeds obtained are above or equal to $4 \mathrm{~m} / \mathrm{s}$ which indicates a high persistence of the wind in this region. 


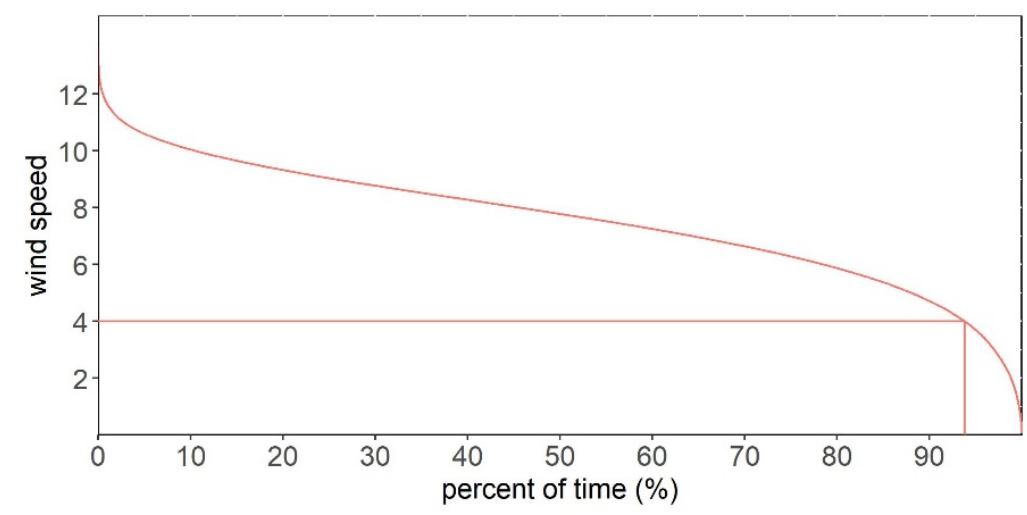

Figure 6. WSDC of the wind speed series at 100m from Fernando de Noronha.

The CPA and PP curves, with $q_{0}=6682$, are shown in Fig. 7. This $q_{0}$ value confirms a high persistence of wind at $100 \mathrm{~m}$ and indicates that the series contains consecutive months with wind speeds useful for generating wind energy. Moreover, the PP curve on the right panel of Fig. 7 demonstrates that the probability of finding a month $(30 \times 24=720)$ with consecutive observations (hours) with useful speeds is about $50 \%$, and that the probability for 5 consecutive months $(150 \times 24=3600)$ is approximately $14 \%$.
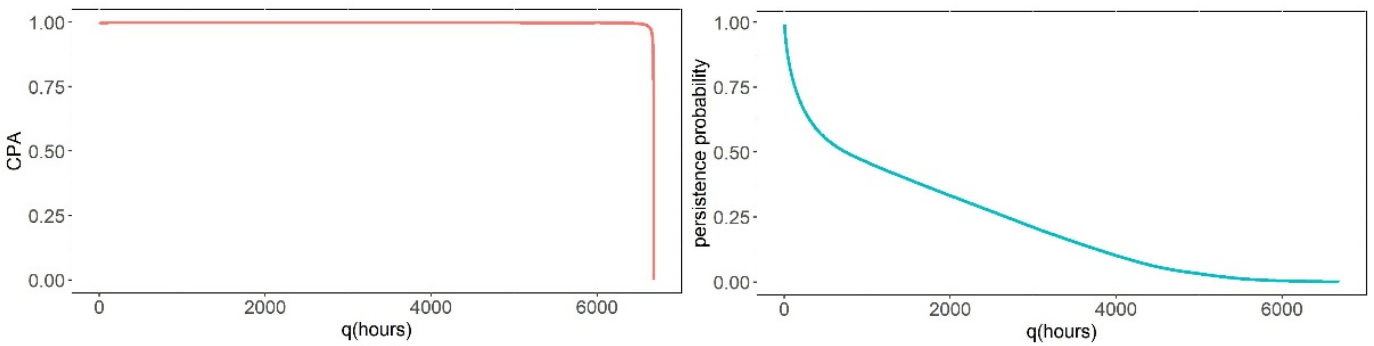

Figure 7. CPA (left panel and PP (right panel) of the wind speed series at $100 \mathrm{~m}$ from Fernando de Noronha.

\section{Conclusions}

This study investigated the persistence of wind speed at a height of $100 \mathrm{~m}$ for the Fernando de Noronha archipelago. Considering the results obtained via CPA, WSDC and the novel Persistence Probability approach (PP), it can be concluded that the island of Fernando de Noronha has a high persistence of wind speed at $100 \mathrm{~m}$ height, as roughly $50 \%$ of $500 \mathrm{~h}$ (20day) intervals demonstrate continuous conditions favorable for energy generation (W's). This suggests that a greater investment in wind energy in this region should be made, although practical economic justification of such investments may require consideration of other factors. 
Moreover, a new measure was introduced in this work to quantify wind persistence based on persistence probability of wind speed useful for generating wind energy. It was also shown that this proposal is simple, and can complement information that is not observed from the conditional probability curve, widely used in the literature.

\section{Availability of data and material}

Manuscript analyses data available on the Internet at https://cds.climate.copernicus.eu.

Code availability Custom code in $\mathrm{C}$, callable from $\mathrm{R}$, available from the authors upon request.

Authors' contributions All authors contributed to the study conception and design. Data collection, formal analysis and investigation were performed by Allan Robert da Silva and Borko Stosic. The first draft of the manuscript was written by Allan Robert da Silva and all authors participated in writing, review and editing of the subsequent versions of the manuscript. All authors read and approved the final manuscript.

\section{Funding Statement}

The authors acknowledge support of Brazilian agency $\mathrm{CNPq}$ through the grants 307445/2018-6 and 304497/2019-3. This study was financed in part by the Coordenação de Aperfeiçoamento de Pessoal de Nível Superior - Brasil (CAPES) - Finance Code 001.

\section{Compliance with ethical standards}

\section{Conflict of Interest}

The authors declare there was no conflict of interest in the conduction of this study.

\section{References}

ABEEólica, Brazilian Wind Energy Association (2019). Annual Wind Energy Report. http://abeeolica.org.br/?s=report

Araújo MSM, Freitas MAV (2008). Acceptance of Renewable Energy Innovation in Brazil Case Study of Wind Energy. Renewable and Sustainable Energy Reviews 12 (2): 584-91. https://doi.org/10.1016/j.rser.2006.03.017.

Archer CL, Caldeira K (2009). Global assessment of high-altitude wind power. Energies, 2(2), 307-319.

C3S. Copernicus Climate Change Service (C3S) Climate Data Store (CDS). DOI: 10.24381/cds.adbb2d47.

Caduff M, Huijbregts MAJ, Hans-Joerg A, Koehler A, Hellweg S (2012). "Wind Power Electricity: The Bigger the Turbine The Greener the Electricity?". Environmental Science \& Technology 46 (9): 4725-33. https://doi.org/10.1021/es204108n. 
Cancino-Solórzano Y, Gutiérrez-Trashorras AJ, Xiberta-Bernat J (2010). Analytical Methods for Wind Persistence: Their Application in Assessing the Best Site for a Wind Farm in the State of Veracruz Mexico. Renewable Energy 35 (12): 2844-52. https://doi.org/10.1016/j.renene.2010.05.008.

Cannon DJ, Brayshaw DJ, Methven J, Coker PJ, Lenaghan D (2015). Using reanalysis data to quantify extreme wind power generation statistics: A 33 year case study in Great

Britain. Renewable Energy, 75, 767-778. https://doi.org/10.1016/j.renene.2014.10.024

Chadee XT, Clarke RM (2014). Large-scale wind energy potential of the Caribbean region using near-surface reanalysis data. Renewable and Sustainable Energy Reviews, 30, 45-58.

Chizfahm A, Yazdi EA, Eghtesad M (2018). Dynamic Modeling of Vortex Induced Vibration Wind Turbines. $\quad$ Renewable Energy $121 \quad$ (June): 632-43. https://doi.org/10.1016/j.renene.2018.01.038.

Gruber K, Regner P, Wehrle S, Zeyringer M, Schmidt, J. (2020). Towards a global dynamic wind atlas: A multi-country validation of wind power simulation from MERRA-2 and ERA5 reanalyses bias-corrected with the Global Wind Atlas. arXiv:2012.05648v1

GWEC, Global Wind Energy Council (2019). Global Wind Report 2019.

https://gwec.net/global-wind-report-2019

Holt E, Wang J (2012). Trends in wind speed at wind turbine height of $80 \mathrm{~m}$ over the contiguous United States using the North American Regional Reanalysis (NARR). Journal of Applied Meteorology and Climatology, 51(12), 2188-2202.

Jamieson P (2018). Innovation in Wind Turbine Design. John Wiley \& Sons Ltd. https://doi.org/10.1002/9781119137924.

Koçak K (2008). Practical Ways of Evaluating Wind Speed Persistence. Energy 33 (1): 6570. https://doi.org/10.1016/j.energy.2007.07.010.

Koçak K (2009). Examination of persistence properties of wind speed records using detrended fluctuation analysis. Energy, 34(11), 1980-1985.

Korkmaz FM, Koçak K (2017). Climatology of Wind Speed Persistence over Turkey. International Journal of Climatology 38 (November): e95-e98. https://doi.org/10.1002/joc.5353.

Kulkarni S, Deo MC, Ghosh S (2015). Effect of climate change on wind persistence at selected Indian offshore locations. Procedia Engineering, 116, 615-622.

Laib M, Golay J, Telesca L, Kanevski M (2018). Multifractal analysis of the time series of daily means of wind speed in complex regions, Chaos, Solitons \& Fractals, 109, 118-127. https://doi.org/10.1016/j.chaos.2018.02.024

Masseran N, Razali AM, Ibrahim K, Zin WW (2012). Evaluating the wind speed persistence for several wind stations in Peninsular Malaysia. Energy, 37(1), 649-656.

https://doi.org/10.1016/j.energy.2011.10.035 
Mazzeo D, Oliveti G, Marsico A (2019). A correction to the unimodal and bimodal truncated normal distributions for a more accurate representation of extreme and calm wind speeds. International Journal of Energy Research, 43(14), 7908-7941.

https://doi.org/10.1002/er.4735

Morgan EC, Lackner M, Vogel RM, Baise LG (2011). Probability distributions for offshore wind speeds. Energy Conversion and Management, 52(1), 15-26.

https://doi.org/10.1016/j.enconman.2010.06.015

Møller H and Pedersen CS (2011). Low-Frequency Noise from Large Wind Turbines. The Journal of the Acoustical Society of America 129 (6): 3727-44. https://doi.org/10.1121/1.3543957.

Olauson J, Bergkvist M (2015). Modelling the Swedish wind power production using MERRA reanalysis data. Renewable Energy, 76, 717-725.

https://doi.org/10.1016/j. renene.2014.11.085

Olauson J (2018). ERA5: The New Champion of Wind Power Modelling?. Renewable Energy 126 (October): 322-31. https://doi.org/10.1016/j.renene.2018.03.056.

Ouarda, Taha BMJ, Charron C (2018). On the mixture of wind speed distribution in a Nordic region. Energy Conversion and Management, 174, 33-44.

https://doi.org/10.1016/j.enconman.2018.08.007

Ouarda Taha BMJ, Charron C, Shin J-Y, Marpu PR, Al-Mandoos AH, Al-Tamimi MH, Ghedira H, Al Hosary TN (2015). Probability distributions of wind speed in the UAE. Energy Conversion and Management, 93, 414-434.

https://doi.org/10.1016/j.enconman.2015.01.036

Ramon J, Lledó L, Torralba V, Soret A, Doblas-Reyes FJ (2019). What Global Reanalysis Best Represents near-Surface Winds?. Quarterly Journal of the Royal Meteorological Society 145 (724): 3236-51. https://doi.org/10.1002/qj.3616.

Rosas P, Studzinski C, Simoni V, Neves F, Fernandes A, Medeiros LHA, et al. (2013). Developing a Supervisory Controller for Hybrid Power System: Fernando De Noronha Island Case. Renewable Energy and Power Quality Journal, March, 1147-51. https://doi.org/10.24084/repqj11.558.

Santos, MO, Stosic T, Stosic BD (2012). Long-term correlations in hourly wind speed records in Pernambuco, Brazil. Physica A: Statistical Mechanics and its Applications, 391(4), 1546-1552. https://doi.org/10.1016/j.physa.2011.08.041

Soulouknga M H, Doka SY, Revanna N, Djongyang N, Kofane TC (2018). Analysis of wind speed data and wind energy potential in Faya-Largeau, Chad, using Weibull distribution. Renewable energy, 121, 1-8. https://doi.org/10.1016/j.renene.2018.01.002 
Figures

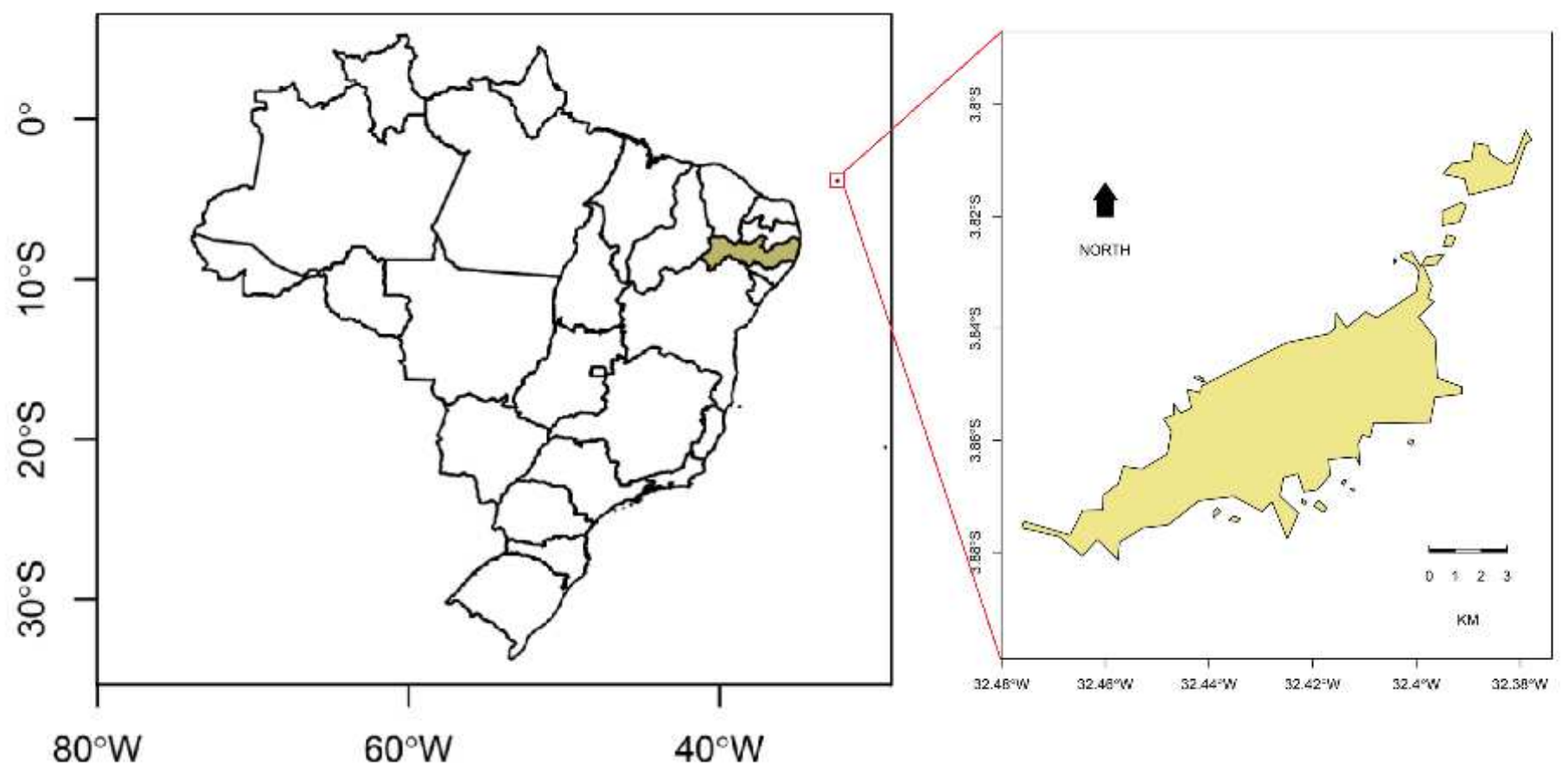

Figure 1

Map of Brazil highlighting the state of Pernambuco, and zoom of the Fernando de Noronha island.

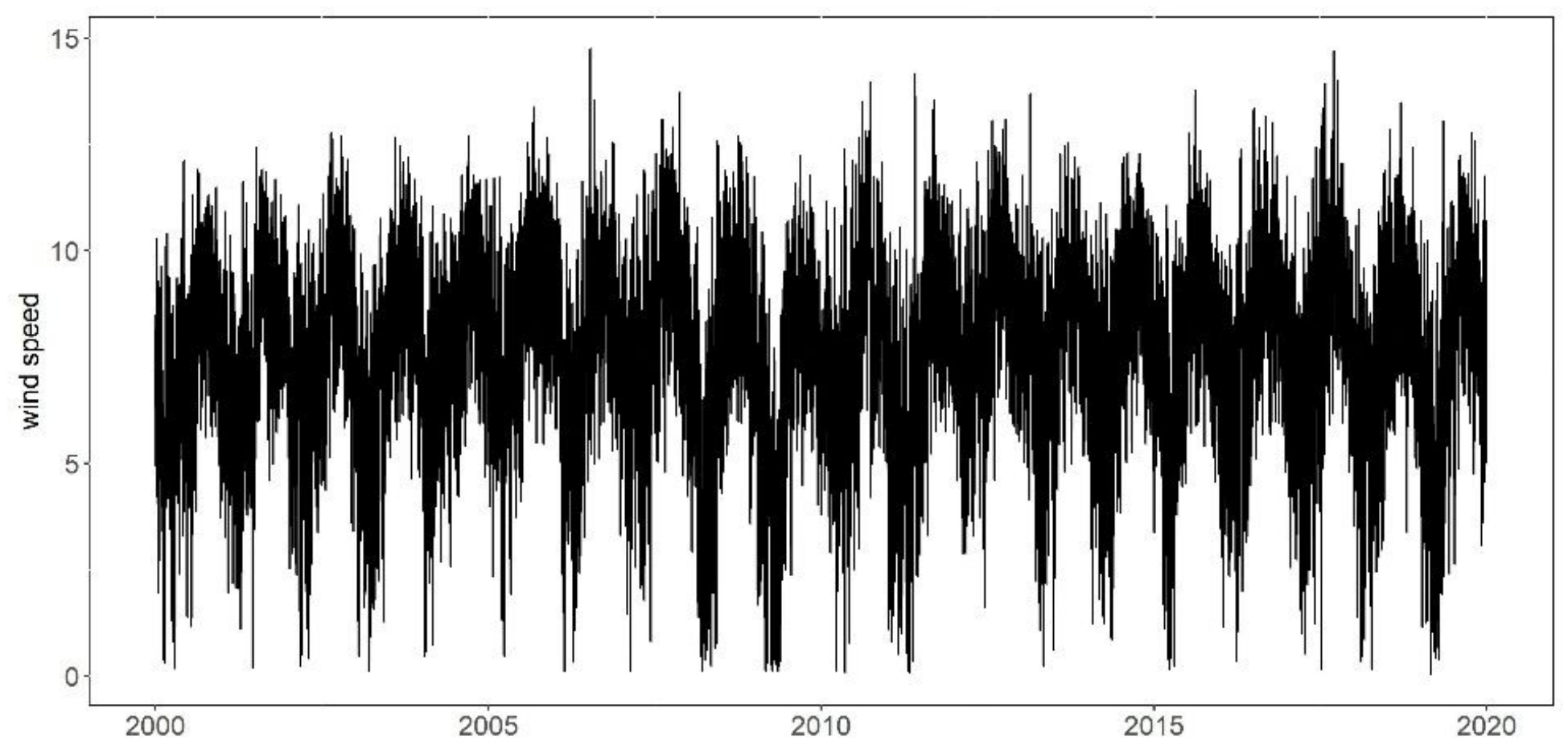

Figure 2 
Time wind speed reanalysis series ERA5 at $100 \mathrm{~m}$
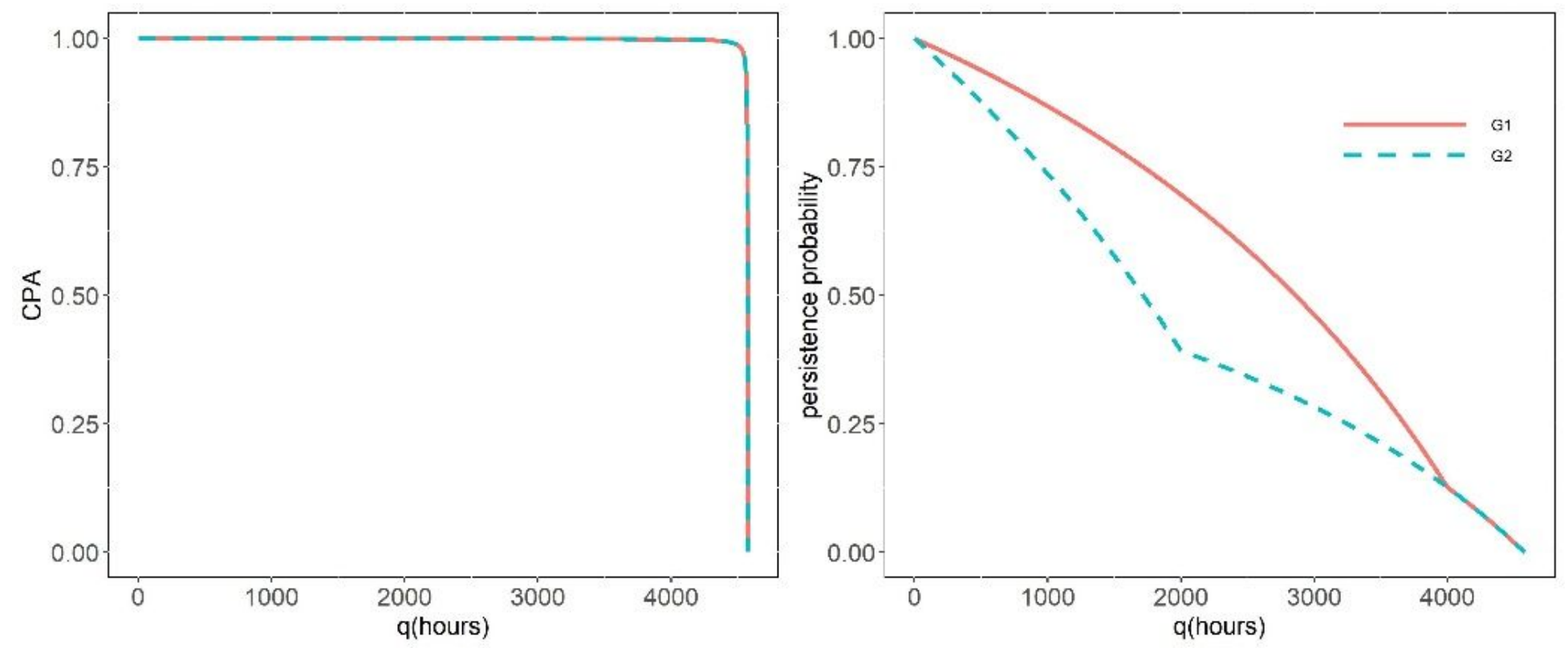

Figure 3

CPA (left panel) and PP (right panel) for G1 and G2 groups (see text).

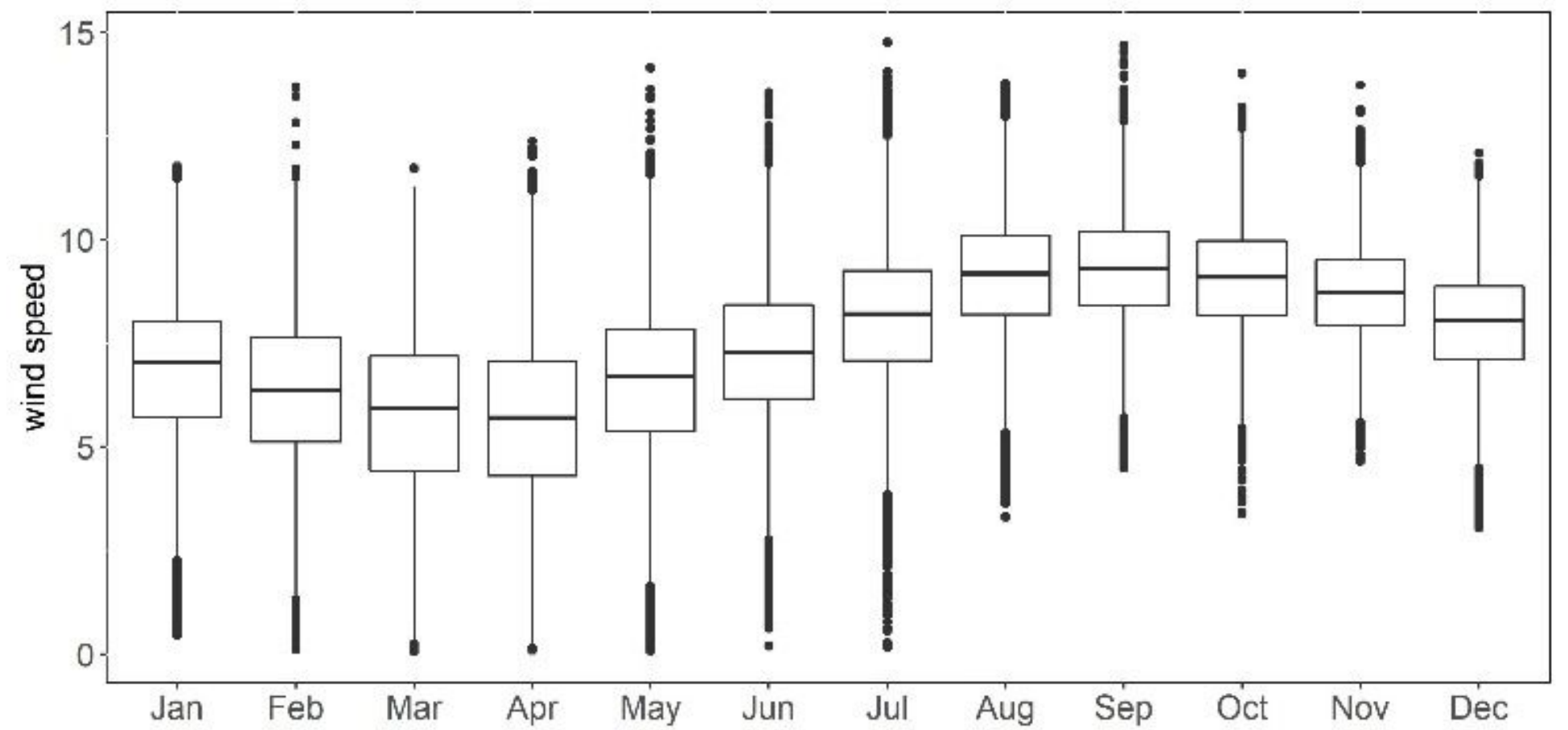

Figure 4

Wind distribution at 100m from Fernando de Noronha per month from 01/01/2000 to 12/31/2019. 


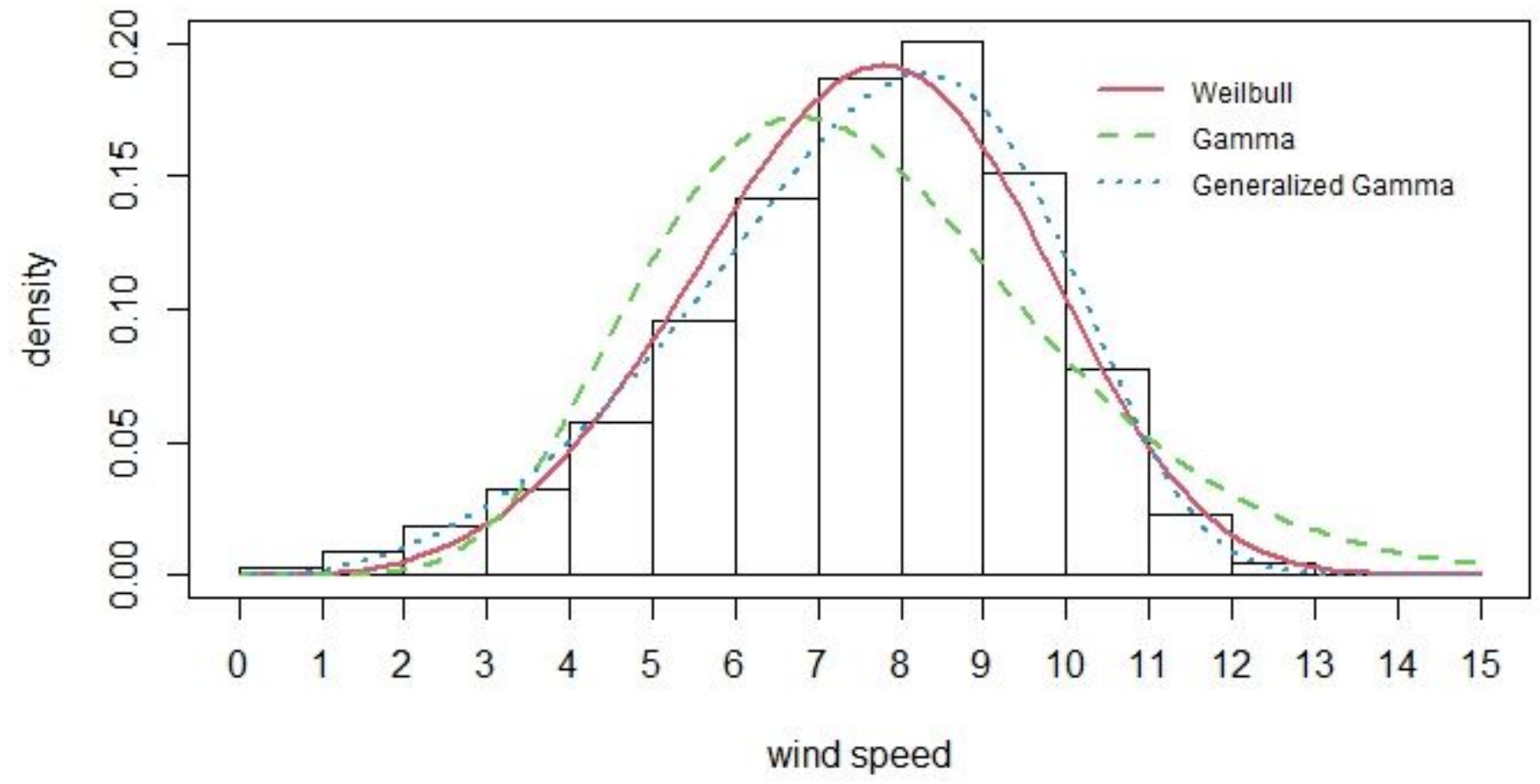

Figure 5

Histogram of the wind speed data with distributions fits.

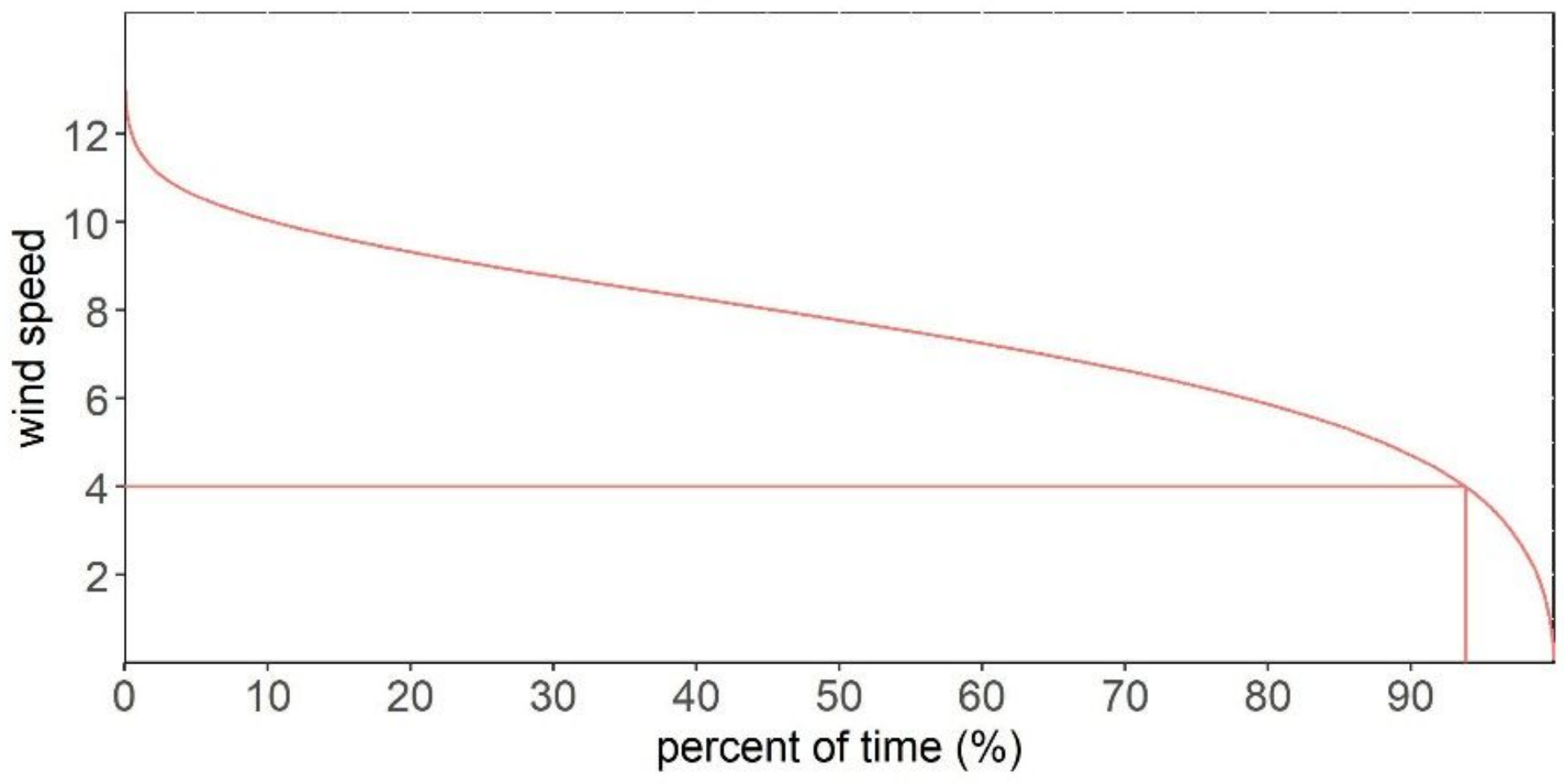

Figure 6 
WSDC of the wind speed series at $100 \mathrm{~m}$ from Fernando de Noronha.
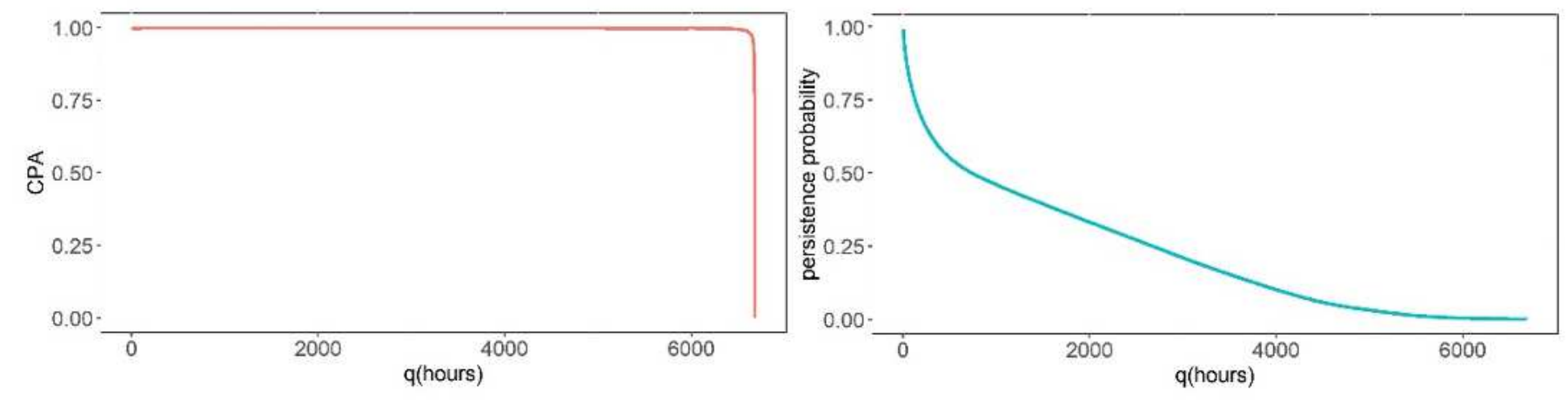

Figure 7

CPA (left panel and PP (right panel) of the wind speed series at 100m from Fernando de Noronha. 